\title{
(6) OPEN ACCESS \\ The neprilysin pathway in heart failure: a review and guide on the use of sacubitril/valsartan
}

\author{
Pardeep S Jhund, John J V McMurray
}

BHF Cardiovascular Research Centre, Institute of Cardiovascular and Medical Sciences, University of Glasgow, Glasgow, UK

\section{Correspondence to} Dr Pardeep S Jhund, British Heart Foundation

Cardiovascular Research Centre, University of Glasgow, 126 University Place, Glasgow G12 8TA, UK; pardeep.jhund@ glasgow.ac.uk

Received 5 October 2015 Accepted 14 April 2016 Published Online First 20 May 2016
CrossMark

\begin{tabular}{l}
\hline To cite: Jhund PS, \\
McMurray JJV. Heart \\
2016;102:1342-1347. \\
\hline
\end{tabular}

\begin{abstract}
Inhibition of neurohumoural pathways such as the renin angiotensin aldosterone and sympathetic nervous systems is central to the understanding and treatment of heart failure (HF). Conversely, until recently, potentially beneficial augmentation of neurohumoural systems such as the natriuretic peptides has had limited therapeutic success. Administration of synthetic natriuretic peptides has not improved outcomes in acute HF but modulation of the natriuretic system through inhibition of the enzyme that degrades natriuretic (and other vasoactive) peptides, neprilysin, has proven to be successful. After initial failures with neprilysin inhibition alone or dual neprilysin-angiotensin converting enzyme (ACE) inhibition, the Prospective comparison of angiotensin receptor neprilysin inhibitor (ARNI) with ACEI to Determine Impact on Global Mortality and morbidity in Heart Failure trial (PARADIGM-HF) trial demonstrated that morbidity and mortality can be improved with the angiotensin receptor blocker neprilysin inhibitor sacubitril/valsartan (formerly LCZ696). In comparison to the ACE inhibitor enalapril, sacubitril/valsartan reduced the occurrence of the primary end point (cardiovascular death or hospitalisation for HF) by $20 \%$ with a $16 \%$ reduction in all-cause mortality. These findings suggest that sacubitril/valsartan should replace an ACE inhibitor or angiotensin receptor blocker as the foundation of treatment of symptomatic patients (NYHA II-IV) with HF and a reduced ejection fraction. This review will explore the background to neprilysin inhibition in $\mathrm{HF}$, the results of the PARADIGM-HF trial and offer guidance on how to use sacubitril/valsartan in clinical practice.
\end{abstract}

The renin angiotensin aldosterone system (RAAS) system is at the core of the pathophysiology of heart failure (HF) and its modulation is central to altering the disease process in HF with reduced ejection fraction (HF-REF). Successive randomised controlled trials have demonstrated that blockade of RAAS improves morbidity and mortality in patients with HF-REF. ${ }^{1-3}$ The prognosis of HF-REF has been improved as a consequence, although it remains poor ${ }^{4}$ as it remains a complex syndrome involving a multitude of neurohormonal pathways. Therefore, further therapies to improve outcomes in these patients are needed.

\section{THE NATRIURETIC PEPTIDE SYSTEM}

The natriuretic peptide system counter regulates the detrimental effects of the upregulation of RAAS that occurs in HF-REF, inhibits secretion of arginine vasopressin and modulates the autonomic nervous system in ways that are likely to be beneficial in this syndrome. ${ }^{5}$ Sodium and water retention and vasoconstriction caused by activation of RAAS and the sympathetic nervous system, and the action of vasopressin, lead to increased ventricular preload and afterload and elevated wall stress which in turn lead to production of pre-pro B-type natriuretic peptide (BNP) which is cleaved to BNP and N-terminal proBNP (NT-proBNP). The release of natriuretic peptides may also be determined by the levels of other neurohormones such as angiotensin II and endothelin. ${ }^{6}$ The peptide BNP acts to promote natriuresis and vasodilation (NT-proBNP is physiologically inactive). Atrial stretch leads to the production of pre-proatrial or A-type natriuretic peptide and ultimately atrial natriuretic peptide (ANP) which has similar biological properties to $\mathrm{BNP}^{5}$ Urodilatin (which is structurally related to ANP), is derived from the same precursor in the kidneys. ${ }^{7}$ C-type natriuretic peptide (CNP) is released from endothelial cells and acts in a paracrine fashion but is only found in low concentrations in circulating blood. ${ }^{5}$ Two strategies have been employed to try and improve outcomes in HF-REF via modulation of this pathway. The first is the administration of exogenous natriuretic peptides. Nesiritide, a recombinant human BNP, initially showed promising beneficial effects on haemodynamics and natriuresis in patients with HF-REF. ${ }^{8}$ However, in a large-scale randomised controlled trial, nesiritide failed to improve outcomes (though it did improve dyspnoea). ${ }^{9}$ Although carperitide (recombinant ANP) is used as a treatment for acute HF in Japan, there is no robust evidence supporting this practice. ${ }^{10}$ The second strategy is to inhibit the breakdown of natriuretic peptides. ANP, BNP, CNP and urodilatin are cleaved and inactivated by a membrane bound endopeptidase, neprilysin (as well as insulin degrading enzyme). Neprilysin is found in a number of tissues but in especially high concentrations in the kidney. Natriuretic peptides are also cleared via the natriuretic peptide clearance receptor (NPRC and NPRC3).

\section{INITIAL NEPRILYSIN INHIBITORS}

Initial attempts at inhibiting neprilysin using an oral (racecodotril ${ }^{11}$ ) and intravenous (candoxatrilat ${ }^{12}$ ) formulation were successful in promoting natriuresis and increasing urinary excretion of ANP. A further neprilysin inhibitor (ecadotril) had similar effects. ${ }^{13}$ However, a study of chronic use of the oral prodrug candoxatril showed that the initial reduction in blood pressure was not sustained and therefore development was stopped. ${ }^{14}$ This might be explained by the finding that neprilysin also breaks down angiotensin II. ${ }^{15-17}$ Therefore inhibiting neprilysin alone, while raising natriuretic peptides levels, also increases angiotensin II levels (and other substrates for neprilysin such as 
endothelin, vasopressin, bradykinin, etc) potentially counteracting the actions of the former peptides.

\section{DUAL NEPRILYSIN AND ACE INHIBITION}

The solution to the problem of lone neprilysin inhibition appeared to be dual blockade of RAAS and the natriuretic peptide system (figure 1). As ACE inhibitors are known to improve outcomes it seemed logical to combine an ACE inhibitor with a neprilysin inhibitor. The combined ACE and neprilysin inhibitor omapatrilat was studied in a large randomised controlled trial against enalapril $10 \mathrm{mg}$ twice daily in the Omapatrilat Versus Enalapril Randomized Trial of Utility in Reducing Events (OVERTURE) trial. ${ }^{18}$ The primary end point, death from any cause or HF hospitalisations were not reduced by omapatrilat. Although other secondary end points suggested a benefit with omapatrilat (death from any cause or cardiovascular (CV) hospitalisation was $9 \%$ lower in the omapatrilat group) the rate of angio-oedema was much higher in the omapatrilat group. Both ACE and neprilysin break down bradykinin and omapatrilat also inhibits aminopeptidase $\mathrm{P}$ which also catabolises bradykinin. Therefore, unintended excessive potentiation of bradykinin and resultant high rates of serious angio-oedema led to the discontinuation of the clinical development of this drug.

\section{ANGIOTENSIN RECEPTOR BLOCKER NEPRILYSIN INHIBITORS}

Combining an angiotensin receptor blocker (ARB) and a neprilysin inhibitor was the logical next step and potential solution to the problem encountered with omapatrilat. The angiotensin receptor neprilysin inhibitor (ARNI) sacubitril/valsartan (formerly known as LCZ696) was designed with the aim of inhibiting neprilysin while blocking the adverse effects of RAAS and reducing bradykinin potentiation. ${ }^{19-21}$ The drug LCZ696 is made of the ARB valsartan and neprilysin inhibitor prodrug sacubitril. As the active metabolite of sacubitril, sacubitrilat (LBQ657), does not inhibit aminopeptidase P, the risk of angio-oedema was expected to be lower than with omapatrilat. ${ }^{19-21}$ Given twice daily, sacubitril/valsartan leads to sustained neprilysin and RAAS inhibition over a $24 \mathrm{~h}$ period addressing one limitation of the OVERTURE trial in which omapatrilat was given as a single large dose once daily. ${ }^{22}$ That approach may have contributed to the significant early postdose hypotension seen with omapatrilat but did not provide sustained inhibition of ACE and neprilysin over $24 \mathrm{~h}$. The systemic exposure delivered by sacubitril/valsartan $97 \mathrm{mg} / 103 \mathrm{mg}$ (200 mg LCZ696) is equivalent to $160 \mathrm{mg}$ of valsartan and neprilysin is almost completely inhibited for up to 12 h. ${ }^{19-21}$

The Prospective comparison of ARNI with ACEI to Determine Impact on Global Mortality and morbidity in Heart Failure trial (PARADIGM-HF) was conducted to test whether $97 \mathrm{mg} / 103 \mathrm{mg}$ twice daily of sacubitril/valsartan was superior to enalapril $10 \mathrm{mg}$ twice daily in reducing the primary end point of CV death or HF hospitalisation. ${ }^{22-24}$ All randomised patients completed a run-in period of 6-8 weeks during which it was required that the target dose of both drugs was tolerated prior to randomisation. Each treatment period (enalapril and sacubitril/valsartan) included a washout period to avoid simultaneous neprilysin and ACE inhibition and the potential risk of angio-oedema (patients with a history of angio-oedema were also excluded). The trial was terminated early, on the recommendation of the Data Monitoring Committee, due to a sustained and highly significant reduction in the risk of the primary composite end point (CV death or HF hospitalisation) and in $\mathrm{CV}$ mortality in the sacubitril/valsartan group compared with the enalapril group. At the end of the trial, there was a $20 \%$ relative risk reduction in the primary end point and each of its components, as well as a $16 \%$ reduction in all-cause mortality. The two major modes of CV death, sudden death and death from worsening HF, were equally and significantly reduced. ${ }^{25}$ Both first hospitalisations for HF and total (including repeat) hospitalisations were also reduced by $21 \%$ and $23 \%$, respectively (figure 2). ${ }^{26}$ Therefore, for every 1000 patients switched

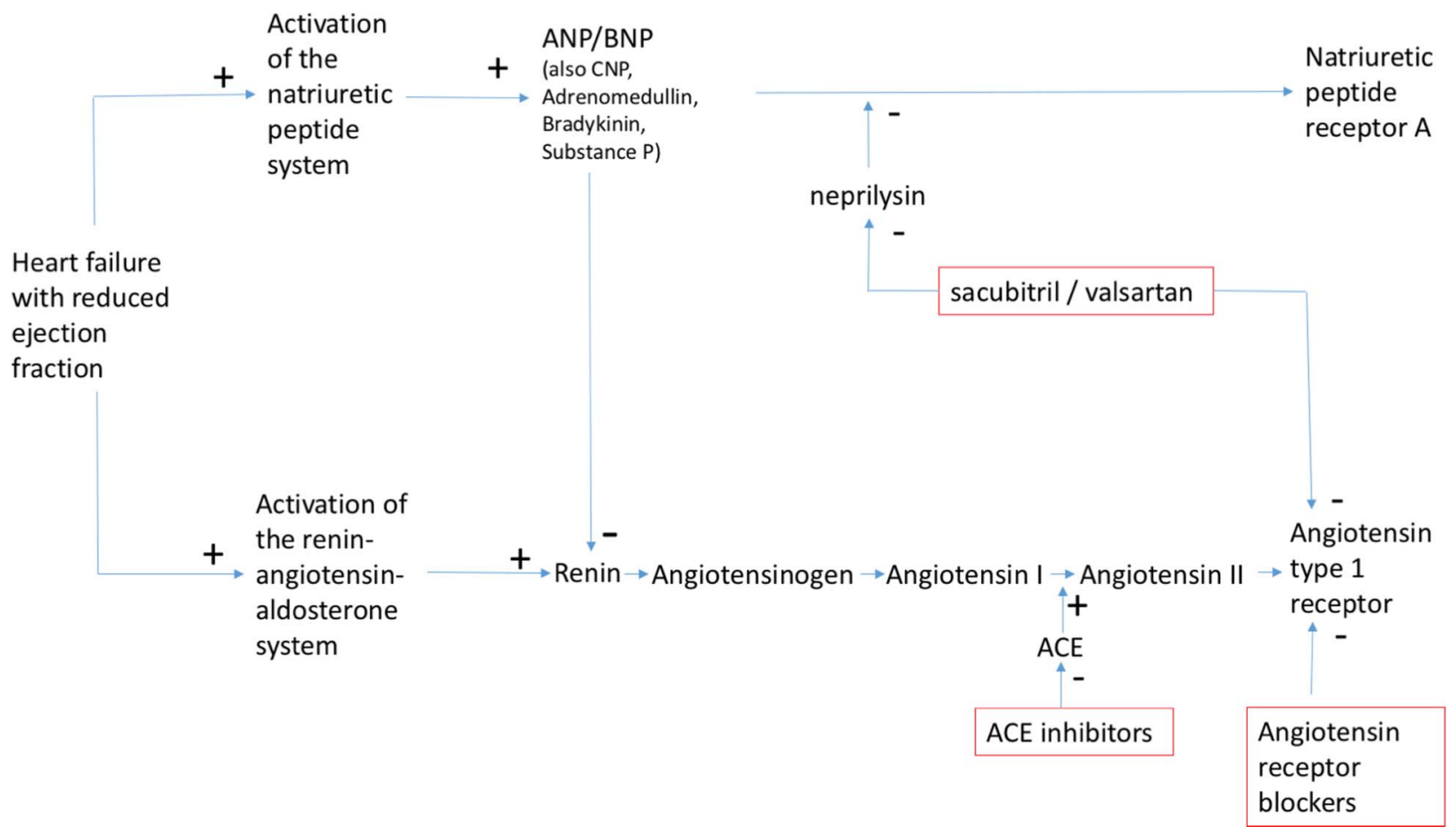

Figure 1 Pathways blocked by ACE inhibitors, angiotensin receptor blockers and neprilysin inhibitors. ANP, atrial natriuretic peptide; BNP, B-type natriuretic peptide; CNP, B-type natriuretic peptide. 


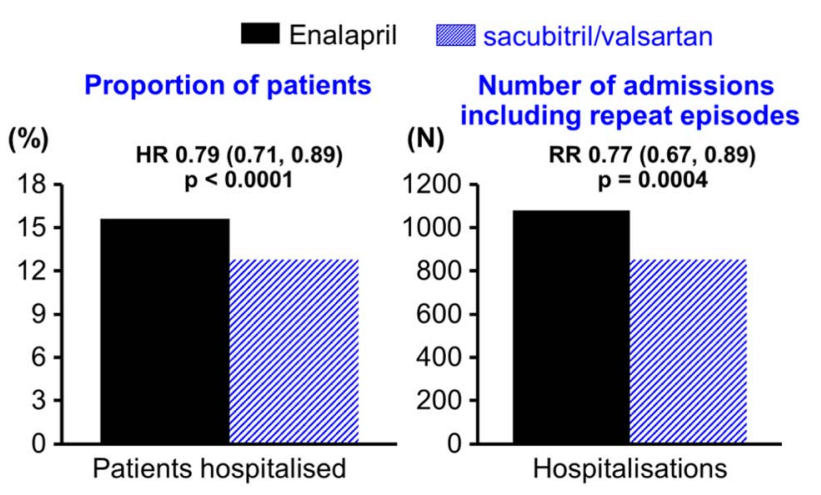

Figure 2 Effect of sacubitril/valsartan on the rate of heart failure (HF) hospitalisations as a time to first event analysis and as a recurrent event analysis of total hospitalisations for. ${ }^{26}$

from enalapril to sacubitril/valsartan, over a median of 27 months, there would be: 47 less primary end points (CV death or HF hospitalisations), 33 less CV deaths, 28 less first hospitalisations for HF (53 less total hospitalisations for HF) and 32 less deaths from any cause. ${ }^{24}$ No convincing or consistent interaction between any of the subgroups and study outcomes were observed. ${ }^{24}$ There was no statistically significant difference in the rate of angio-oedema with sacubitril/valsartan although numerically more cases were observed than in the enalapril group (19 patients in the sacubitril/valsartan group and 10 cases in the enalapril group, $\mathrm{p}=0.13) .{ }^{24}$ Hypotension was significantly more common with sacubitril/valsartan than with enalapril (14\% vs $9 \%$ in the in the sacubitril/valsartan and enalapril groups respectively, $\mathrm{p}<0.001)$, although this rarely led to studydrug discontinuation $(0.9 \%$ and $0.7 \%$ in the sacubitril/valsartan and enalapril groups respectively, $\mathrm{p}=0.38)$. Conversely, renal dysfunction, hyperkalaemia and cough were less common with sacubitril/valsartan than with enalapril. Subsequent analyses of PARADIGM-HF have confirmed that the relative reductions in morbidity and mortality and differential rates of adverse events were similar across all ages ${ }^{27}$ (figure 3) and baseline risk of death as determined by risk-scoring systems. ${ }^{28}$

\section{ROBUSTNESS OF RESULTS OF PARADIGM-HF AND REGULATORY APPROVAL}

Regulatory approval of a new drug requires demonstration of effectiveness and safety in either two trials with a two-sided $\mathrm{p}<0.05$ OR a single, large, internally consistent, multicentre study with $\mathrm{p}<0.00125$. $^{29}$ PARADIGM-HF fulfils these criteria. It was large (8399 patients randomised), highly statistically significant $(\mathrm{p}=0.0000004)$, internally consistent (lack of subgroup interactions), multicentre (sites were located in 47 countries), and there were large effects on morbidity and mortality (CV death or hospitalisation for HF was reduced by $20 \%$ and allcause mortality by $16 \%$ ). If we ignore the argument that to repeat the trial would be unethical, to achieve such a statistically significant result on the primary end point would require four
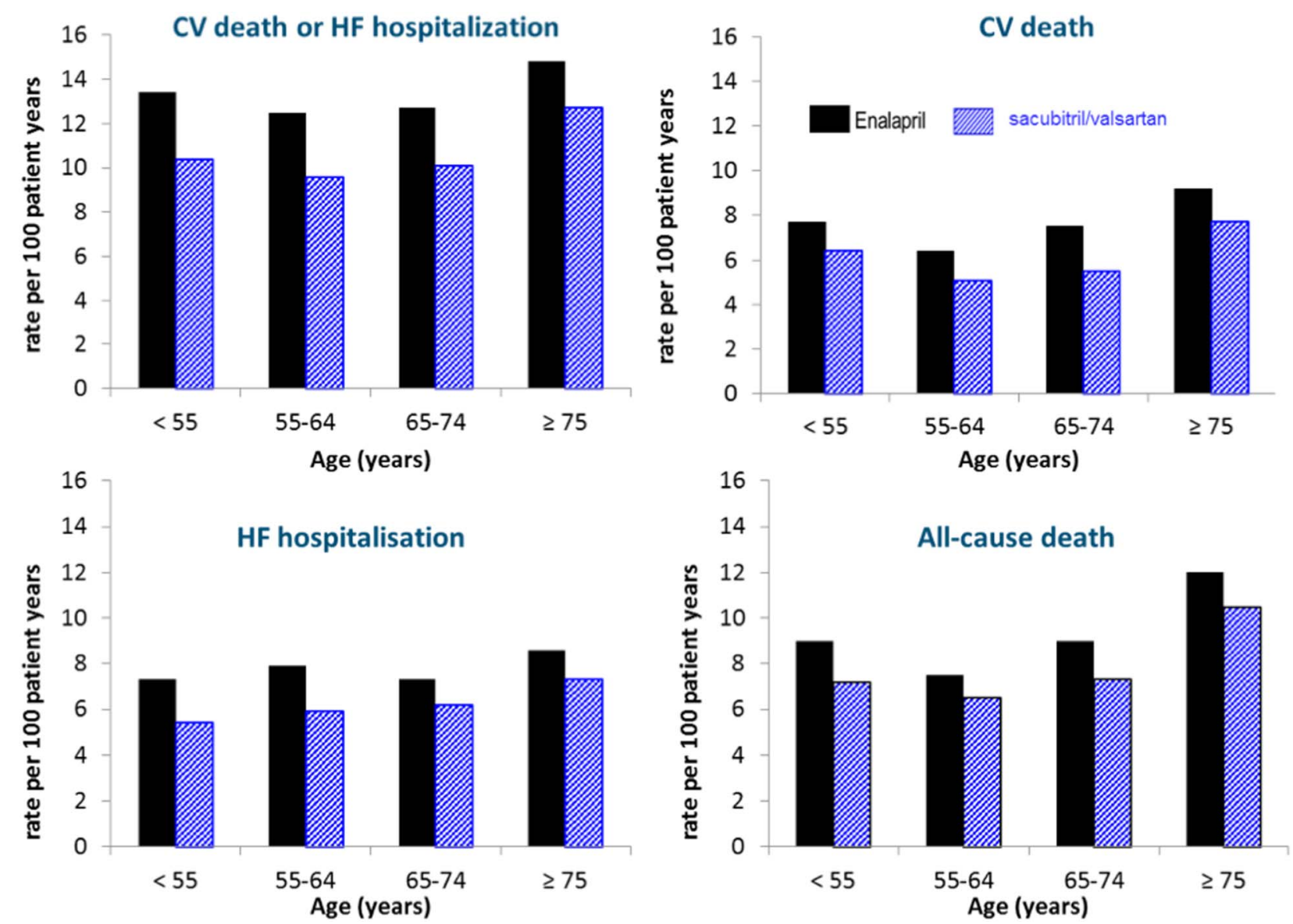

Figure 3 Effect of sacubitril/valsartan on the rate of primary end point and component and all-cause mortality in patients randomised in the PARADIGM-HF trial according to age group. ${ }^{27} \mathrm{p}$ for interaction for cardiovascular (CV) death or heart failure (HF) hospitalisation=0.94, for CV death $p$ for interaction $=0.92$, for HF hospitalisation $p$ for interaction $=0.81$ and all-cause death $p$ for interaction $=0.99$. PARADIGM-HF, Prospective comparison of ARNI with ACEI to Determine Impact on Global Mortality and morbidity in Heart Failure. 
or five trials each with a $p$ value of $<0.05$ to have the same strength of evidence as provided by a single trial with a $p$ value $=0.0000004$ (table 1). Put another way, if sacubitril/valsartan was in fact no better than enalapril the chances of observing the treatment difference that was found in PARADIGM-HF is less than one in a million. ${ }^{30}$ We believe that this finding creates a unique question for the HF guideline committee. 'Level A' evidence conventionally requires data from multiple randomised trials or a well conducted meta-analysis (table 2). Usually, a solitary randomised trial would confer a B level of evidence. Does the robustness of the findings of PARADIGM-HF equate to two trials or a meta-analysis?

\section{WHO SHOULD BE PRESCRIBED SACUBITRIL/VALSARTAN?}

The only evidence for the use of sacubitril/valsartan is in patients with HF-REF. An outcomes trial of sacubitril/valsartan versus valsartan in patients with HF and preserved ejection fraction, the Prospective comparison of ARni with Arb Global Outcomes in heart failure with preserved ejectioN fraction (PARAGON-HF) is currently still recruiting (ClinicalTrials.gov Identifier:NCT01920711). We also do not have robust data on the use of this drug in hospitalised patients (although some data are available $\mathrm{e}^{31}$ a trial is underway ClinicalTrials.gov Identifier: NCT02661217) or those with HF complicating an acute myocardial infarction. Therefore, if we consider the inclusion and exclusion criteria of the PARADIGM-HF trial, sacubitril/valsartan can be given to: adult patients with HF, New York Heart Association (NYHA) II-IV and a reduced ejection fraction $(\leq 40 \%)$ on a $\beta$-blocker and MRA as recommended by guidelines, with a systolic blood pressure of $\geq 100 \mathrm{~mm} \mathrm{Hg}$ and estimated glomerular filtration rate (eGFR) $\geq 30 \mathrm{~mL} / \mathrm{min} / 1.73 \mathrm{~m}^{2}$ and potassium $\leq 5.2 \mathrm{mmol} / \mathrm{L}$ (figure 4). The US Food and Drug Administration (FDA) and European Medicines Agency (EMA) prescribing information is consistent with these groups. ${ }^{32} 33$ Although further inclusion criteria were stipulated in the trial (patients had to have a BNP $\geq 150 \mathrm{pg} / \mathrm{mL}$ (NTpro-BNP $\geq 600 \mathrm{pg} / \mathrm{mL}$ ) or if hospitalised with HF a BNP $\geq 100 \mathrm{pg} / \mathrm{mL}$ (NTpro-BNP $\geq 400 \mathrm{pg} / \mathrm{mL}$ )) these are not part of the FDA or EMA prescribing information, presumably because most patients with HF-REF exceed these thresholds, ${ }^{34-36}$ there was no interaction between baseline natriuretic peptide concentration and the effect of treatment ${ }^{24}$ and because there is no biological basis for assuming sacubitril/valsartan would lose its effectiveness below these thresholds. Supporting the prescribing information

Table 1 Number of trials with a $p$ value $<0.05$ to provide the same level of evidence as PARADIGM-HF on the primary outcome and cardiovascular death

\begin{tabular}{|c|c|c|c|}
\hline $\begin{array}{l}\text { Number of } \\
\text { trials with } \\
p<0.05 \\
\text { showing } \\
\text { efficacy }\end{array}$ & $\begin{array}{l}p \text { value required } \\
\text { by } 1 \text { trial to } \\
\text { provide the same } \\
\text { strength of } \\
\text { evidence }\end{array}$ & $\begin{array}{l}\text { PARADIGM-HF p } \\
\text { value for primary } \\
\text { end point }\end{array}$ & $\begin{array}{l}\text { PARADIGM-HF p } \\
\text { value for CV } \\
\text { death }\end{array}$ \\
\hline 1 trial & 0.05 & & \\
\hline 2 trials* & $0.00125^{*}$ & & 0.00008 \\
\hline 3 trials & 0.00003125 & & $\begin{array}{l}\text { (equivalent to } 2-3 \\
\text { trials at } p<0.05 \text { ) }\end{array}$ \\
\hline 4 trials & 0.00000078 & \multirow{2}{*}{$\begin{array}{l}0.0000004 \\
\text { (equivalent to } 4-5 \\
\text { trials at } p<0.05 \text { ) }\end{array}$} & \\
\hline 5 trials & 0.0000000195 & & \\
\hline
\end{tabular}

Table 2 Class of recommendation and level of evidence definitions used by major guideline bodies

\begin{tabular}{|c|c|}
\hline $\begin{array}{l}\text { Classes of } \\
\text { recommendations }\end{array}$ & Definition \\
\hline Class I & $\begin{array}{l}\text { Evidence and/or general agreement that a given } \\
\text { treatment or procedure is beneficial, useful, effective. }\end{array}$ \\
\hline Class II & $\begin{array}{l}\text { Conflicting evidence and/or a divergence of opinion } \\
\text { about the usefulness/efficacy of the given treatment } \\
\text { or procedure. }\end{array}$ \\
\hline Class Ila & $\begin{array}{l}\text { Weight of evidence/opinion is in favour of } \\
\text { usefulness/efficacy. }\end{array}$ \\
\hline Class IIb & $\begin{array}{l}\text { Usefulness/efficacy is less well established by } \\
\text { evidence/opinion. }\end{array}$ \\
\hline Class III & $\begin{array}{l}\text { Evidence or general agreement that the given } \\
\text { treatment or procedure is not useful/effective, and in } \\
\text { some cases may be harmful. }\end{array}$ \\
\hline Levels of evidence & Definition \\
\hline Level of evidence $A$ & $\begin{array}{l}\text { Data derived from multiple randomised clinical trials } \\
\text { or meta-analyses. }\end{array}$ \\
\hline Level of evidence B & $\begin{array}{l}\text { Data derived from a single randomised clinical trial } \\
\text { or large non-randomised studies. }\end{array}$ \\
\hline Level of evidence C & $\begin{array}{l}\text { Consensus of opinion of the experts and/or small } \\
\text { studies, retrospective studies, registries. }\end{array}$ \\
\hline
\end{tabular}

from the FDA and EMA, cost-effectiveness analyses in private ${ }^{37}$ and public 3839 healthcare systems confirm that sacubitril/valsartan is cost-effective.

\section{WHEN SHOULD A PATIENT BE PRESCRIBED SACUBITRIL/ VALSARTAN?}

Currently the prescribing information from FDA notes that sacubitril/valsartan should be used in patients in place of an ACE inhibitor or other ARB that is, that patients on these treatments should be switched to ARNI. ${ }^{32}$ We are lacking evidence for patients with newly diagnosed HF-REF. Should they be established on an ACE inhibitor (or ARB) for at least 1 month after which time they would have been eligible for PARADIGM-HF that is, to switch to sacubitril/valsartan? The FDA seems to have decided otherwise as their labelling also gives recommendations on how to start sacubitril/valsartan in ACE inhibitor/ARB-naïve patients (see below). ${ }^{32}$ This is probably logical (if not entirely evidence-based), as the lower risks of renal dysfunction and hyperkalaemia with sacubitril/valsartan may enable more patients to achieve optimal RAAS inhibition. Furthermore, conducting a trial in ACE inhibitor/ARB-naïve patients would be nearly impossible-recruitment would be slow (given the much smaller number of patients with incident heart failure) and cross-over from the ACE inhibitor group to the sacubitril/valsartan group is likely to be very high, confounding interpretation of outcomes. In the Safety and Tolerability of Initiating LCZ696 in Heart Failure Patients (TITRATION) study $^{31}$ of dose escalation strategies of sacubitril/valsartan $(\mathrm{N}=498)$ patients who were ACE inhibitor or ARB-naïve $(7 \%)$ and hospitalised (11\%) were included. Rates of adverse events were similar to those reported in PARADIGM-HF.

Furthermore, apart from these practical considerations, there is no plausible scientific reason to believe the results of such a trial would be different than PARADIGM-HF and an analysis of the PARADIGM-HF trial by subgroup of duration of HF (those with $\mathrm{HF}$ for $\leq 1$ year, $1-5$ years and $>5$ years) revealed no interaction between duration of $\mathrm{HF}$ and benefit from sacubitril/valsartan ( $\mathrm{p}$ for interaction for the primary outcome $=0.27$ ). ${ }^{24}$ 


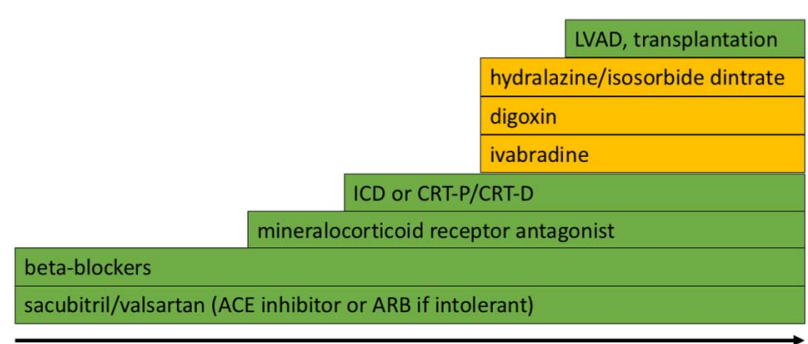

Ongoing symptoms NYHA class II- IV

Legend

Improves mortality +/- morbidity

Improves morbidity

Figure 4 Stepwise treatment of patients with symptomatic (NYHA IIIV) heart failure with reduced ejection fraction. Progressive therapies should be added in a stepwise fashion. Where two or more options exist on a step the most appropriate therapy for the patient based on concomitant medication or the presence of other patient factors should be made. NYHA, New York Heart Association; ARB, angiotensin receptor blocker; $A C E$, angiotensin converting enzyme inhibitor; ICD, implantable cardioverter defibrillator; CRT-P, cardiac resynchronisation therapy-pacemaker; CRT-D, cardiac resynchronisation therapydefibrillator; LVAD, left ventricular assist device.

\section{HOW SHOULD SACUBITRIL/VALSARTAN BE PRESCRIBED?}

Sacubitril/valsartan should not be given in conjunction with another $\mathrm{ARB}$ or renin inhibitor (because of the risk of renal impairment and hyperkalaemia) or an ACE inhibitor (risk of renal impairment, hyperkalaemia and angio-oedema). Due to the potential risk of angio-oedema when used concurrently with an ACE inhibitor, sacubitril/valsartan must not be started for at least $36 \mathrm{~h}$ after discontinuing an ACE inhibitor. ${ }^{32}$ Patients and carers should discard any remaining doses to reduce the risk of accidental dosing. The starting dose of sacubitril/valsartan is $49 \mathrm{mg} / 51 \mathrm{mg}$ twice daily. This should be reduced in certain groups (table 3 ). The dose should be doubled every $2-4$ weeks as tolerated by the patient to the maximum dose of $97 \mathrm{mg} / 103 \mathrm{mg}$ twice daily.

Patients should also be prescribed other evidence-based drugs ( $\beta$-blocker, mineralocorticoid receptor antagonist, ivabradine and digoxin) and devices (cardiac resynchronisation therapy (CRT), implantable cardioverter defibrillator (ICD)), as appropriate.

\section{SIDE EFFECTS AND CAUTIONS}

Renal function and potassium should be monitored as for any other RAAS blocker. Similarly blood pressure should also be monitored and we would suggest that the drug is not started in those with a systolic blood pressure of $<100 \mathrm{~mm} \mathrm{Hg}$ in keeping with the exclusion criteria of the trial. In the event of the development of hypotension, renal impairment or hyperkalaemia, evaluation of the potential causes should be sought and appropriate changes made. For example, reducing the dose of other non-essential blood pressure-lowering drugs, adjusting the dose of diuretics, discontinuing other drugs such as non-steroidal anti-inflammatory drugs. Of course dose reduction or discontinuation of sacubitril/ valsartan should also be considered in these scenarios after assessment of the patient. The development of angio-oedema should lead to immediate discontinuation and treatment with appropriate therapy until it has resolved. Permanent treatment discontinuation was not common in the PARADIGM-HF trial with rates of discontinuation similar in the sacubitril/valsartan group and the enalapril group for hypotension and hyperkalaemia (all $<1 \%) .{ }^{24}$ Rates of discontinuation for renal impairment were lower in the sacubitril/valsartan group compared with the enalapril group $(0.7 \%$ vs $1.4 \%$ respectively, $\mathrm{p}=0.002)$.

One final issue worthy of note is that of treatment monitoring. Monitoring the treatment and prognosis of patients with HF by tracking natriuretic peptides is still an area of great interest. ${ }^{40}$ Sacubitril/valsartan increases levels of circulating BNP therefore BNP is not useful for monitoring the prognosis of these patients. $^{26}$ NT-proBNP is still useful as changes in the levels of this inactive peptide continue to reflect reduced pre-proBNP secretion as a result of reduction in wall stress. ${ }^{26}$ Neprilysin has a higher affinity for other natriuretic peptides such as ANP and CNP than it does for BNP. Therefore, other natriuretic peptides may be more useful to monitor treatment response and the level of neprilysin inhibition, although whether this would predict prognosis is unclear.

\section{HEART FAILURE WITH PRESERVED EJECTION FRACTION}

There is also experience with sacubitril/valsartan in heart failure with preserved ejection fraction (HF-PEF). In the Prospective comparison of ARNI with ARB on Management Of heart failUre with preserved ejection fracTion (PARAMOUNT) trial, 301 patients with HF-PEF were randomised to valsartan or sacubitril/ valsartan. ${ }^{41}$ NT-proBNP fell in the latter group along with reductions in NYHA class and left atrial volumes. On the basis of these findings and the favourable effects seen in PARADIGM-HF a large multicentre randomised outcomes trial of sacubitril/valsartan versus valsartan, PARAGON-HF, is currently recruiting.

\section{SUMMARY}

Even in patients with HF-REF with mild symptoms, apparently 'stable' on conventional treatment, it is clear that morbidity and

Table 3 Starting dose and dose titration for sacubitril/valsartan in a variety of patient populations with heart failure and reduced ejection fraction (HF-REF)

\begin{tabular}{|c|c|c|}
\hline Population with HF-REF & $\begin{array}{l}\text { Starting dose of sacubitril/ } \\
\text { valsartan }\end{array}$ & Uptitration and target dose \\
\hline No patient characteristics requiring caution or dose reduction & $49 \mathrm{mg} / 51 \mathrm{mg}$ twice daily & \multirow{6}{*}{$\begin{array}{l}\text { Uptitration by doubling of dose every } 2-4 \text { weeks until a } \\
\text { target dose of } 97 \mathrm{mg} / 103 \mathrm{mg} \text { twice daily is reached. }\end{array}$} \\
\hline $\begin{array}{l}\text { Currently only taking a low or just low target dose of ACE inhibitor or } \\
\text { ARBt }\end{array}$ & $24 \mathrm{mg} / 26 \mathrm{mg}$ twice daily & \\
\hline No ACE inhibitor or ARB in the past & $24 \mathrm{mg} / 26 \mathrm{mg}$ twice daily & \\
\hline eGFR $<30 \mathrm{~mL} / \mathrm{min} / \mathrm{m}^{2} \ddagger$ & 24 mg/26 mg twice daily & \\
\hline Moderate hepatic impairment (Child-Pugh class B) & 24 mg/26 mg twice daily & \\
\hline Elderly & $24 \mathrm{mg} / 26 \mathrm{mg}$ twice daily & \\
\hline
\end{tabular}


mortality remains high and that substitution of sacubitril/valsartan for an ACE inhibitor leads to rapid and substantial improvement in outcomes. Therefore, it is our view that an ARNI should replace an $\mathrm{ACE}$ inhibitor (or an ARB) as a foundation of treatment for HF-REF and already this view is reflected in new guidelines. ${ }^{42} 43$ The results of the PARAGON-HF trial will determine whether sacubitril/valsartan has any place in the management of HF-PEF. The speed of adoption of sacubitril/valsartan will depend on a number of different factors, including cost-effectiveness.

Contributors PSJ and JJVM wrote and revised the manuscript.

Competing interests PSJ has consulted for Novartis. JJVM's employer, the University of Glasgow, was/is being paid for his time spent as Executive Committee member/cochair of PARADIGM-HF and PARGON-HF.

Provenance and peer review Commissioned; externally peer reviewed.

Open Access This is an Open Access article distributed in accordance with the Creative Commons Attribution Non Commercial (CC BY-NC 4.0) license, which permits others to distribute, remix, adapt, build upon this work non-commercially, and license their derivative works on different terms, provided the original work is properly cited and the use is non-commercial. See: http://creativecommons.org/ licenses/by-nc/4.0

\section{REFERENCES}

1 [No authors listed]. Effect of enalapril on survival in patients with reduced left ventricular ejection fractions and congestive heart failure. The SOLVD Investigators. N Engl J Med 1991;325:293-302.

2 [No authors listed]. Effects of enalapril on mortality in severe congestive heart failure. Results of the Cooperative North Scandinavian Enalapril Survival Study (CONSENSUS). The CONSENSUS Trial Study Group. N Engl J Med 1987:316:1429-35.

3 Cohn JN, Tognoni G. A randomized trial of the angiotensin-receptor blocker valsartan in chronic heart failure. N Engl J Med 2001:345:1667-75.

4 Jhund PS, Macintyre K, Simpson CR, et al. Long-term trends in first hospitalization for heart failure and subsequent survival between 1986 and 2003: a population study of 5.1 million people. Circulation 2009;119:515-23.

5 Daniels LB, Maisel AS. Natriuretic peptides. J Am Coll Cardiol 2007:50:2357-68.

6 Rademaker MT, Charles CJ, Espiner EA, et al. Combined inhibition of angiotensin II and endothelin suppresses the brain natriuretic peptide response to developing heart failure. Clin Sci 2004:106:569-76.

7 Schulz-Knappe P, Forssmann K, Herbst F, et al. Isolation and structural analysis of "urodilatin", a new peptide of the cardiodilatin-(ANP)-family, extracted from human urine. Klin Wochenschr 1988;66:752-9.

8 Publication Committee for the VMAC Investigators (Vasodilatation in the Management of Acute CHF). Intravenous nesiritide vs nitroglycerin for treatment of decompensated congestive heart failure: a randomized controlled trial. JAMA 2002:287:1531-40.

9 O'Connor CM, Starling RC, Hernandez AF, et al. Effect of nesiritide in patients with acute decompensated heart failure. N Engl J Med 2011;365:32-43.

10 Hata N, Seino Y, Tsutamoto $T$, et al. Effects of carperitide on the long-term prognosis of patients with acute decompensated chronic heart failure: the PROTECT multicenter randomized controlled study. Circ J 2008;72:1787-93.

11 Gros C, Souque A, Schwartz JC, et al. Protection of atrial natriuretic factor against degradation: diuretic and natriuretic responses after in vivo inhibition of enkephalinase (EC 3.4.24.11) by acetorphan. Proc Natl Acad Sci USA 1989:86:7580-4

12 Northridge DB, Alabaster CT, Connell JMC, et al. Effects of UK 69 578: a novel atriopeptidase inhibitor. Lancet 1989;334:591-3.

13 Kahn JC, Patey M, Dubois-Rande JL, et al. Effect of sinorphan on plasma atrial natriuretic factor in congestive heart failure. Lancet 1990:335:118-19.

14 Bevan EG, Connell JMC, Doyle J, et al. Candoxatril, a neutral endopeptidase inhibitor: efficacy and tolerability in essential hypertension. J Hypertens 1992;10:607-13.

15 Richards AM, Wittert GA, Espiner EA, et al. Effect of inhibition of endopeptidase 24.11 on responses to angiotensin II in human volunteers. Circ Res 1992:71:1501-7

16 Dalzell JR, Seed A, Berry C, et al. Effects of neutral endopeptidase (neprilysin) inhibition on the response to other vasoactive peptides in small human resistance arteries: studies with thiorphan and omapatrilat. Cardiovasc Ther 2014:32:13-18.

17 Ferro CJ, Spratt JC, Haynes WG, et al. Inhibition of neutral endopeptidase causes vasoconstriction of human resistance vessels in vivo. Circulation 1998:97: 2323-30.

18 Packer M, Califf RM, Konstam MA, et al. Comparison of omapatrilat and enalapril in patients with chronic heart failure: the Omapatrilat Versus Enalapril Randomized Trial of Utility in Reducing Events (OVERTURE). Circulation 2002;106:920-6.
19 Ruilope LM, Dukat A, Böhm M, et al. Blood-pressure reduction with LCZ696, a novel dual-acting inhibitor of the angiotensin II receptor and neprilysin: a randomised, double-blind, placebo-controlled, active comparator study. Lancet 2010:375:1255-66.

$20 \mathrm{Gu} J$, Noe A, Chandra P, et al. Pharmacokinetics and pharmacodynamics of LCZ696, a novel dual-acting angiotensin receptor-neprilysin inhibitor (ARNi). J Clin Pharmacol 2010;50:401-14.

21 Hegde LG, Yu C, Renner T, et al. Concomitant angiotensin AT1 receptor antagonism and neprilysin inhibition produces omapatrilat-like antihypertensive effects without promoting tracheal plasma extravasation in the rat. J Cardiovasc Pharmacol 2011:57:495-504.

22 McMurray JJV, Packer M, Desai AS, et al, on behalf of the PARADIGM-HF Committees, Investigators. Dual angiotensin receptor and neprilysin inhibition as an alternative to angiotensin-converting enzyme inhibition in patients with chronic systolic heart failure: rationale for and design of the Prospective comparison of ARN with ACEI to Determine Impact. Eur J Heart Fail 2013;15:1062-73.

23 McMurray JJV, Packer M, Desai AS, et al. Baseline characteristics and treatment of patients in prospective comparison of ARNI with ACEl to determine impact on global mortality and morbidity in heart failure trial (PARADIGM-HF). Eur J Heart Fail 2014;16:817-25

24 McMurray JJV, Packer M, Desai AS, et al. Angiotensin-neprilysin inhibition versus enalapril in heart failure. N Engl J Med 2014;371:993-1004.

25 Desai AS, McMurray JJV, Packer M, et al. Effect of the angiotensin-receptorneprilysin inhibitor LCZ696 compared with enalapril on mode of death in heart failure patients. Eur Heart J 2015;36:1990-7.

26 Packer M, McMurray JJV, Desai AS, et al. Angiotensin receptor neprilysin inhibition compared with enalapril on the risk of clinical progression in surviving patients with heart failure. Circulation 2015:131:54-61.

27 Jhund PS, Fu M, Bayram E, et al, PARADIGM-HF Investigators and Committees. Efficacy and safety of LCZ696 (sacubitril-valsartan) according to age: insights from PARADIGM-HF. Eur Heart J 2015:36:2576-84.

28 Simpson J, Jhund PS, Silva Cardoso J, et al. Effect of LCZ696, compared with enalapril, according to baseline risk in the Prospective comparison of ARNI with ACEI to Determine Impact on Global Mortality and morbidity in Heart Failure trial (PARADIGM-HF). J Am Coll Cardiol 2015:66:2059-71.

29 Guidance for industry-Providing evidence of effectiveness for human drug and biological products. U.S. Department of Health and Human Services, May 1998. (cited 30 September 2015). http://www.fda.gov/downloads/Drugs/.../Guidances/ ucm078749.pdf

30 Pocock SJ, McMurray JJV, Collier TJ. Making sense of statistics in clinical trial reports: part 1 of a 4-part series on statistics for clinical trials. J Am Coll Cardiol 2015:66:2536-49.

31 Senni M, McMurray JJV, Wachter R, et al. Initiating sacubitril/valsartan (LCZ696) in heart failure: results of TITRATION, a double-blind, randomised comparison of two up-titration regimens. Eur J Heart Fail 2016 May 12. doi: 10.1002/ejhf.548.

32 U.S. Food and Drug Administration. ENTRESTO (sacubitril and valsartan). Highlights of prescribing information. (cited 30 September 2015). http://www.accessdata.fda. gov/drugsatfda docs/label/2015/2076200rig1s000lbl.pdf

33 European Medicines Agency. Entresto: EPAR Product information. http://www.ema. europa.eu/docs/en_GB/document_library/EPAR_-_Product_Information/human/ 004062/WC500197536.pdf

34 Cowie MR, Struthers AD, Wood DA, et al. Value of natriuretic peptides in assessment of patients with possible new heart failure in primary care. Lancet 1997;350:1349-53.

35 Dunlay SM, Gerber Y, Weston SA, et al. Prognostic value of biomarkers in heart failure: application of novel methods in the community. Circ Heart Fail 2009:2:393-400

36 Bosselmann $\mathrm{H}$, Egstrup M, Rossing $\mathrm{K}$, et al. Prognostic significance of cardiovascular biomarkers and renal dysfunction in outpatients with systolic heart failure: a long term follow-up study. Int J Cardiol 2013;170:202-7.

37 King JB, Shah RU, Bress AP, et al. Cost-effectiveness of Sacubitril-Valsartan combination therapy compared with enalapril for the treatment of heart failure with reduced ejection fraction. JACC Heart Fail 2016:4:392-402.

38 (NICE) NI for CE. Appraisal consultation document Sacubitril valsartan for treating symptomatic chronic heart failure with reduced ejection fraction. https://www.nice. org.uk/guidance/GID-TAG516/documents/appraisal-consultation-document

39 Scottish Medicines Consortium. Product details sacubitril/valsartan. https://www. scottishmedicines.org.uk/SMC_Advice/Advice/1132_16_sacubitril_valsartan_Entresto

40 Troughton R, Michael Felker G, Januzzi JL. Natriuretic peptide-guided heart failure management. Eur Heart J 2014;35:16-24.

41 Solomon SD, Zile M, Pieske B, et al. The angiotensin receptor neprilysin inhibitor LCZ696 in heart failure with preserved ejection fraction: a phase 2 double-blind randomised controlled trial. Lancet 2012;380:1387-95.

42 Moe GW, Ezekowitz JA, O'Meara E, et al, Canadian Cardiovascular Society. The 2014 Canadian Cardiovascular Society Heart Failure Management Guidelines Focus Update: anemia, biomarkers, and recent therapeutic trial implications. Can J Cardiol 2015;31:3-16.

43 Scottish Intercollegiate Guidelines Network. Management of chronic heart failure. 2016. http://www.sign.ac.uk/guidelines/fulltext/147/index.html 